\title{
USE THE REIMPLANTED TOOTH AS ABUTMENT FOR FIXED PARTIAL DENTURE
}

Golmoradizadeh Ali

1. Reader, Department of Prosthodontics, Centro Escolar University, Prosthodontic \& Oral Surgery Section.

\section{CORRESPONDING AUTHOR:}

Golmoradizadeh Ali,

26C. tower3.dansalan garden,

Mandaluyong, Manila,

Philippines 1550.

E-mail: ali2ph@yahoo.com

ABSTRACT: OBJECTIVE: Use of the fixed partial denture is more favorable than the removable partial denture for my patient, she complained about edentulism in upper right side and a little discomfort with second upper premolar. Clinical examination shows the tooth was crown less and radio graphically tooth had a big periapical lesion with poor prognosis. METHOD: After root canal treatment and extraction the tooth, clean and irrigate the socket, we are implanted it with hydroxyapatite again and follow the patient for six months. After six months, radio graph shows that the tooth was in ideal condition without mobility, then the tooth has used as an abutment for fixed partial denture with canine and 2nd molar in order to have a better prognosis we used semi precision attachment, and follow her for three years. RESULT: Three years follow the patient shows the tooth is in an acceptable condition radio-graphically without mobility and patient was comfortable esthetically and functionally. CONCLUSION: In my opinion in this case use of the hydroxyapatite, crown lengthening during the re- implantation and use the semi precision attachment was the reason of increase the prognosis after treatment

INTRODUCTION: Fixed partial denture nowadays are more acceptable for patients than removable because of aesthetic, function and more confidence purposes. But not all cases are suitable for fixed partial denture, like the patients with long span edentulous area or with not reliable abutment. So save the good abutments and provide other conditions of oral cavity are the best things that the dentist can do for the patients to have an ideal fixed partial denture [7]. Save the natural teeth is more comfortable for the patients and is near to our goal in conservative dentistry, in previous study the researchers was able to use a new technique with aid of hydroxyapatite to save a irremediable tooth, and recommended to continue observation of the tooth condition when it was loaded under the force, In this case, used it as an abutment for fixed partial denture. Before somebody used the reimplanted tooth, as an abutment for fixed bridge, but the most problems with the reimplanted teeth without medium objective like hydroxyapatite is increase the risk of root resorption,[1] and also because of ankylosis phenomenon in most reimplanted teeth use the rigid fixed bridge in long span edentulous with more than two abutment will cause apply extra force to another abutments that are not reimplanted and have normal periodontal ligament. So in these cases like my case the best option is use a medium like hydroxyapatite to have a better prognosis after reimplantation and reduction chance of rejection by the body as a foreign body and also prevention of root resorption due to osseointegration of bone. We also used the semi precision attachment in this case in order to reduce function or extra force to the abutments. Semi precision attachment in 


\section{CASE REPORT}

this case compensated the immovability of the reimplanted tooth with the other two abutments.[9]

METHOD AND MATERIALS: In this case patient was 43 years old, she complained about 2nd premolar upper right side. The near adjacent teeth were canine and 2nd molar. Clinical examination shows the tooth was crownless, with a big periapical lesion involved the periradicular also with initial root resorption in palatal root. Tentative diagnosis was chronic preapical periodontitis. After root canal treatment we extracted the tooth, clean the socket and reimplanted tooth again, but due to very low crown root ratio we adjusted the crown length during reimplantation to prevention of crown lengthening or force eruption afterwards. Then, splinted to the near adjacent for ten days. After six months radiographic examination shows, the tooth is in healthy condition without any periapical lesion. And, ready for any prosthodontic treatment. So we prepare the tooth for fixed partial denture and took impression, after fabricate the bridge by the laboratory we cement it and follow the patient for three years.

RESULT: After following the patient, every six months with radiograph for three years, everything was in acceptable condition without mobility and any other failure factor. Patient could chew normally without pain or any discomfort and esthetically contented

CONCLUSION: Use of the new method than usual method may be able to help the dentist and researcher to save teeth due to a variety of cases. In my opinion, in this case use of the hydroxyapatite, crown lengthening during the reimplantation and use the semi precision attachment was the reason of increase the prognosis after treatment. due to risk of ankylosis use of semi precision attachment recommended to prevent of injury to the supporting structure of reimplanted tooth, and patient had maximum function without any pain or mobility of the abutment during of the observation period. At last use of the natural abutment it is our responsibility in conservative dentistry and it will be safe and more comfortable for the patients, in prevention of edentulism, bone resorption and other negative effects.

DISCUSSION: Use the reimplanted tooth as an abutment is not common in dentistry, due to risk of insufficient supporting and ankylosis in some cases; but with use of precision or semi precision attachment, we can balance the force to the abutment and prevent of injury to the reimplanted tooth due to excessive load. Use of precision and semi precision attachments in fixed partial denture is done in previous studies with high rate of success due to Stress distribution of abutments and base displacement with precision attachment [7]. Extra coronal Precision attachments are normally resilient to allow free movement of the prosthesis to distribute potentially destructive forces or loads away from the abutments to supportive bone and tissue. Three distinctive movements are defined in function Hinge, Vertical, and, rotational [21].

\section{REFERENCES:}

1. Peterson, Edward Ellis, James R.Hupp,Myron Tucker.(1998).Advanced prostethic surgery.

2. Myron R.Tucker.Oral\&maxillofacial surgery .3rd edition.(pp329-331) 
3. Peterson,Edward Ellis,James R.Hupp,Myron TuckerBiologic Cocsideration for Osteointegration.Edwin A.McGuimphy\&Peter E.Larson. Oral\&maxillofacial surgery $.3^{\text {rd }}$ edition .(1998). (pp 357)

4. Peterson,Edward Ellis,James R.Hupp,Myron Tucker.Wound Repair.James R.Hupp. Oral\&maxillofacial surgery . .(1998) $3^{\text {rd }}$ edition(pp 57)

5. Galden Wagnild\&Kathy Mueller.(1995).Restoration of endodontically treated tooth.Aldridge E.Wilder.JR.Pathways Of the Pulp.3rd edition. (pp 786)

6. Neville, Damm, Allen, Bouquot.Palpal \&Periapical Disease. Neville. Oral \& Maxillofacial Pathology. .(2009) (pp120)

7. Newman Takei. CarranzaPrepration of the periodontium for restorative dentistry, preprosthetic surgery. Philip R.Melnick. Clinical Periodontology. .(2006). (pp1042)

8. Newman Takei Carranza.Tooth Suppoting Structures.JosephP.Fiorellini.David M.Kim,Satoshi O.Ishikwa. Clinical Periodontology. .(2006) (pp68)

9. Vinod Kapoor.Transplantation of tissues.Vinod Kapoor. Oral\&maxillofacial surgery.2nd edition. (2002) (pp498)

10. Vinod KapoorAllogenic Grafts. Vinod Kapoor. Oral\&maxillofacial surgery.2nd edition.(2002)..(pp505)

11. Vinod Kapoor.Contraindication for dental implant. Vinod Kapoor. Oral\&maxillofacial surgery.2 $2^{\text {nd }}$ edition.(2002).(pp576)

12. Vinod Kapoor. complication in oral surgery. Vinod Kapoor. Oral\&maxillofacial surgery.2 $2^{\text {nd }}$ edition. (2002). (pp623)

13. Neville, Damm, Allen, Bouquot.Ankylosis.Bouguot. . Oral \& Maxillofacial Pathology.3rd edition.(2009).(pp 75)

14. Neville, Damm, Allen, Bouquot.Periapical Cyst.Neville. Oral \& Maxillofacial Pathology. .(2009) $3^{\text {rd }}$ edition.(pp 131)

15. Anderson,Kahnberg,Pogrel.(2010).Osteointegration in Irradiation tissue.Tony Pogrel. Oral\&maxillofacial surgery.(pp 174)

16. Anderson,Kahnberg,Pogrel.Extraction of teeth ,indication for extraction.Tony Pegrel . Oral\&maxillofacial surgery. .(2010). (pp 181)

17. Anderson,Kahnberg,Pogrel. Autotransplantation of the teeth.Tony Pogrel. Oral\&maxillofacial surgery. (2010). (pp 286).

18. http://www.ncbi.nlm.nih.gov/pubmed/17227381

19. http://www.dentalfind.com/info/reimplantation\#b

20. http://www.ncbi.nlm.nih.gov/pmc/articles/PMC1952935/

21. http://www.preat.com/extracoronal.htm

22. http://ieeexplore.ieee.org/xpl/freeabs_all.jsp?arnumber $=710600$

23. http://en.wikipedia.org/wiki/Hydroxylapatite

24. http://onlinelibrary.wiley.com/doi/10.1002/(SICI)10974636(199802)39:2\%3C190::AID-JBM4\%3E3.0.CO;2-K 


\section{CASE REPORT}

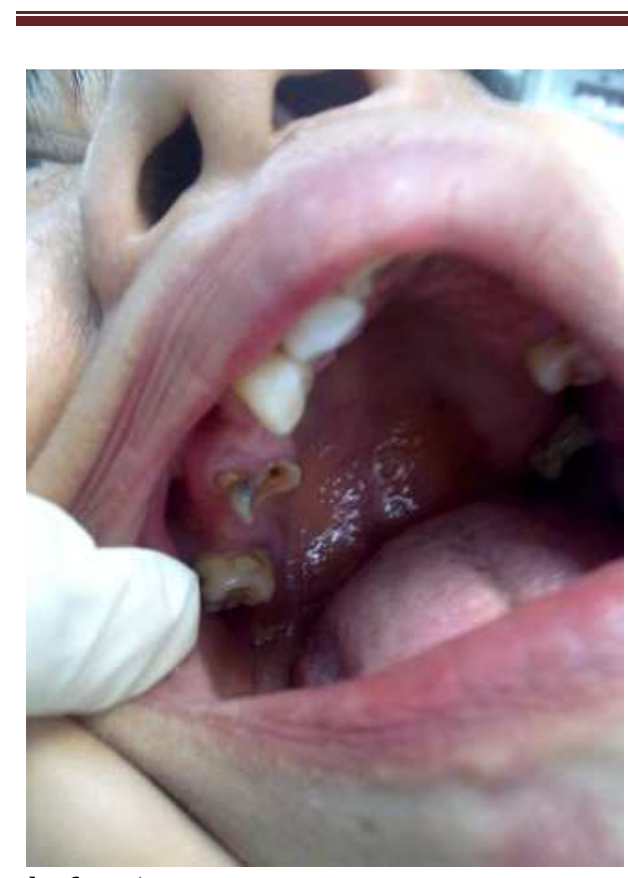

before1

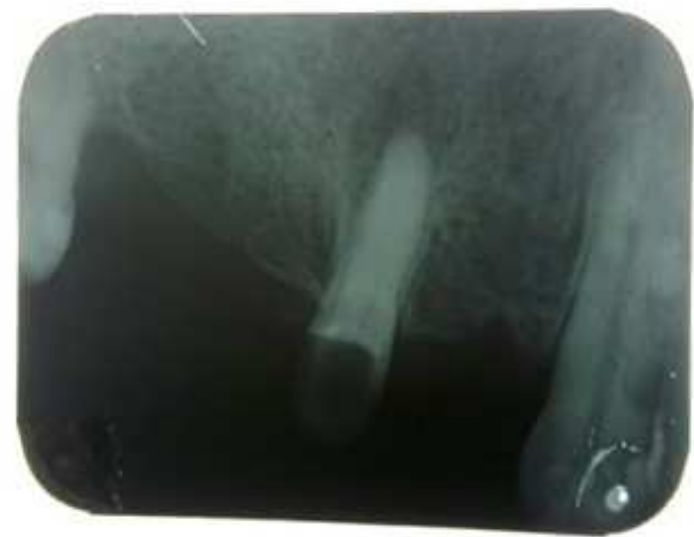

before22

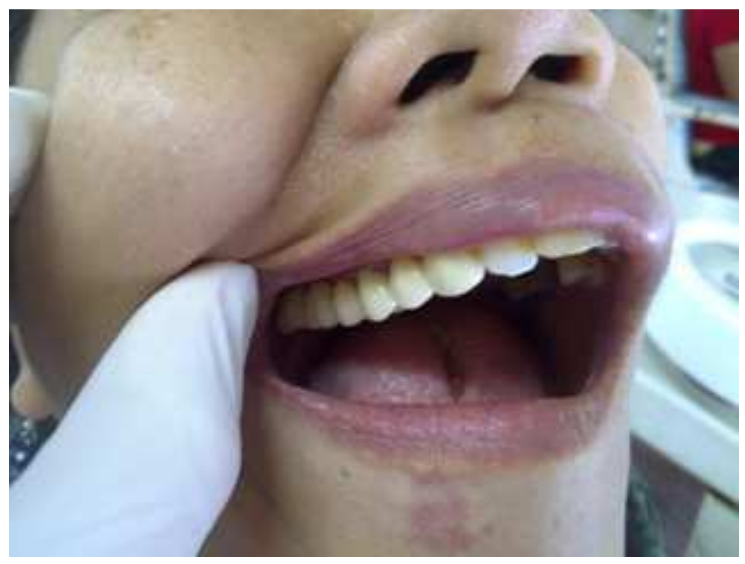

After

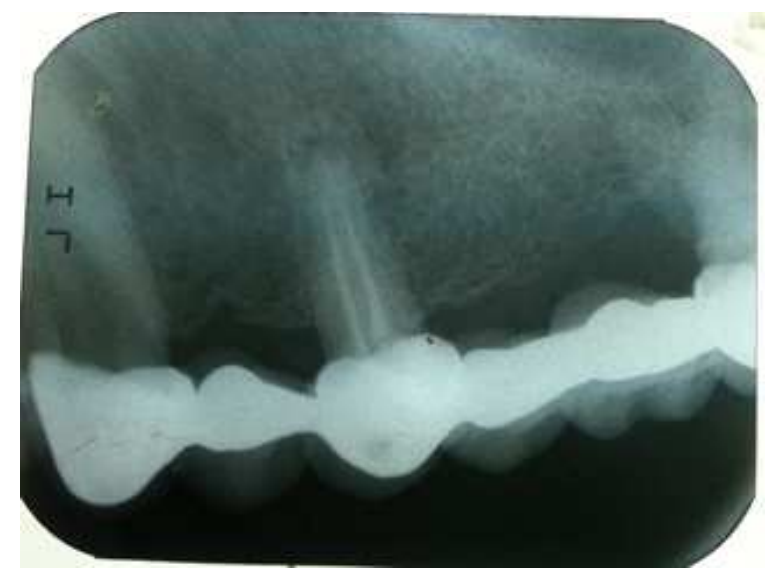

After-2 